\title{
Characteristic Fatigue Life Research on the Centrifugal Impeller
}

\author{
R. Gayathri, R. Mercy Shanthi, Musica S R
}

\begin{abstract}
The researched work quite essentially deals with the resoluteness of the safety and structural integrity of the centrifugal impeller in withstanding the forces impacted on the targeted materials Ti-6Al-4V and Au2gn. In order to counteract the effects prevalent as a result of profound instabilities such as surging, stalling and choking, the materials were subjected to an intense comparative study, undertaken with respect to primary parameters such as good strength yield, in addition to dispensing a rotational speed of 20000 rpm. The preliminary solid modeling was executed using CATIAV5. Structural Analysis is carried out using ANSYS software in order to establish their strengths together with the location of maximum stress and strain. 2D FEM simulation was done on the impeller. Furthermore the number of cycles to failure was computed using the best amongst the known strain - based life estimation methods. From the modal analysis the ubiquitous critical mode shape along with the frequency at which the maximum relative displacement occurs were obtained. Finally, Ti-6Al-4V was affirmed to be better than Au2gn.
\end{abstract}

Index Terms-Impeller, fatigue, stress analysis, vibration effects, strain-based life estimation method.

\section{INTRODUCTION}

The centrifugal flow compressor is a single or two stage units employing an impeller to accelerate the air and a diffuser to produce the required pressure rise. The impeller consists of a forged disc with integrated radial disposed vanes on one or both sides forming convergent passages in conjunction with the compressor casing. To ease the air from axial flow in the entry duct on to the rotating impeller, the vanes in the centre of impeller are curved in the direction of rotation.

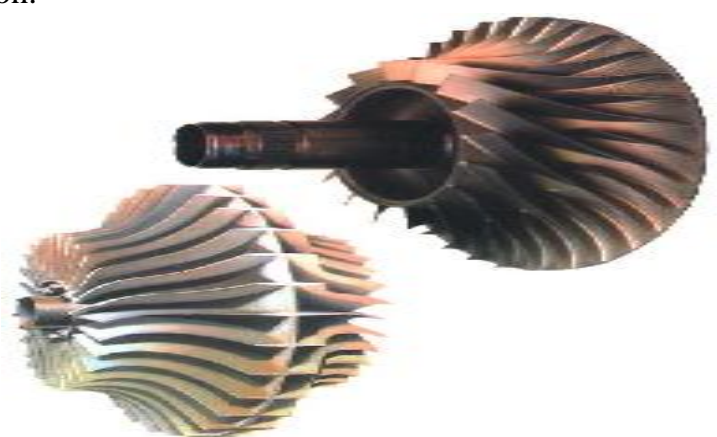

Fig.1 Centrifugal Compressor

II.PROBLEM FORMULATION

Revised Version Manuscript Received on 10, September 2019.

R. Gayathri, Assistant professor, Karunya Institute of Technology and Sciences, Coimbatore, Tamilnadu, India. (Email: gayathri@karunya.edu)

R. Mercy Shanthi, Associate professor, Karunya Institute of Technology and Sciences, Coimbatore, Tamilnadu, India. (Email: mercyshanthi@karunya.edu)

Musica S R, Assistant professor, Karunya Institute of Technology and Sciences, Coimbatore, Tamilnadu, India. (Email: musica@karunya.edu)
The analysis was carried out for centrifugal loading due to rotation. Also other loading such as bending due to gas pressure and temperature loads. The chosen generator speed was 50500rpm. Among these centrifugal loading due to rotation of blade contributes towards stress induced Temperature stresses are found out due to temperature loading from the actual working condition of the engine. The combined effects of temperature and structure loads were found out in the subsequent structural analysis.

\section{III.ANSYS}

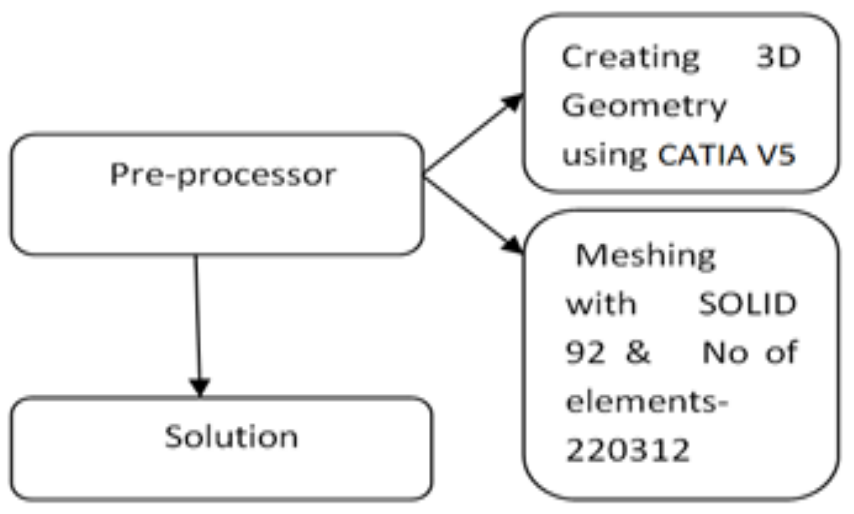

Fig.2 Steps involved in ANSYS

\section{IV.MATERIAL SELECTION FOR CENTRIFUGAL COMPRESSOR}

The material selection process involves the following major operation:

1. Analysis of the material application problem.

2. Translation of the materials application requirement to materials property values.

\begin{tabular}{|c|c|c|c|c|}
\hline $\begin{array}{c}\text { Mater } \\
\text { ial } \\
\text { type }\end{array}$ & $\begin{array}{c}\text { Ultimate } \\
\text { strength } \\
\text { (MPa) }\end{array}$ & $\begin{array}{c}\text { Von } \\
\text { Mises } \\
\text { stress (or) } \\
\text { working } \\
\text { stress } \\
\text { (MPa) }\end{array}$ & $\begin{array}{c}\text { Factor of } \\
\text { safety }\end{array}$ & $\begin{array}{c}\text { Total } \\
\text { Mechanical } \\
\text { strain }\end{array}$ \\
\hline $\begin{array}{c}\text { Au- } \\
\text { 2gn }\end{array}$ & 413 & 244.76 & 1.69 & 0.00355 \\
\hline $\begin{array}{c}\text { Ti- } \\
\text { 6Al- } \\
\text { 4V }\end{array}$ & 940 & 356.326 & 2.64 & 0.003601 \\
\hline
\end{tabular}


From literature survey, Au2gn and Ti6Al4V are suggested for structural analysis.

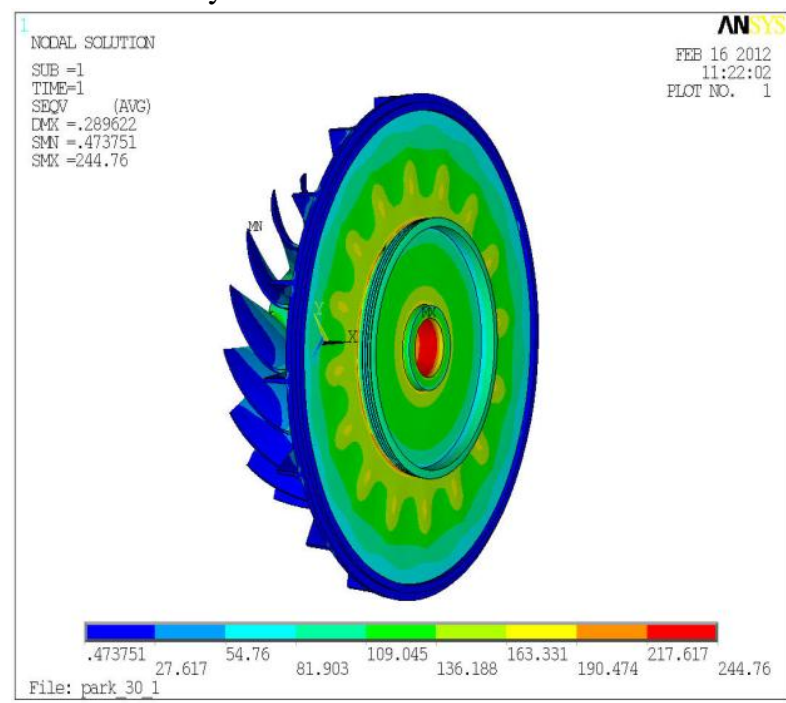

Fig.3 Von-Mises stress for Au2gn. Max Von-Misesstressis occurs at hub i.e. 217.76Mpa.

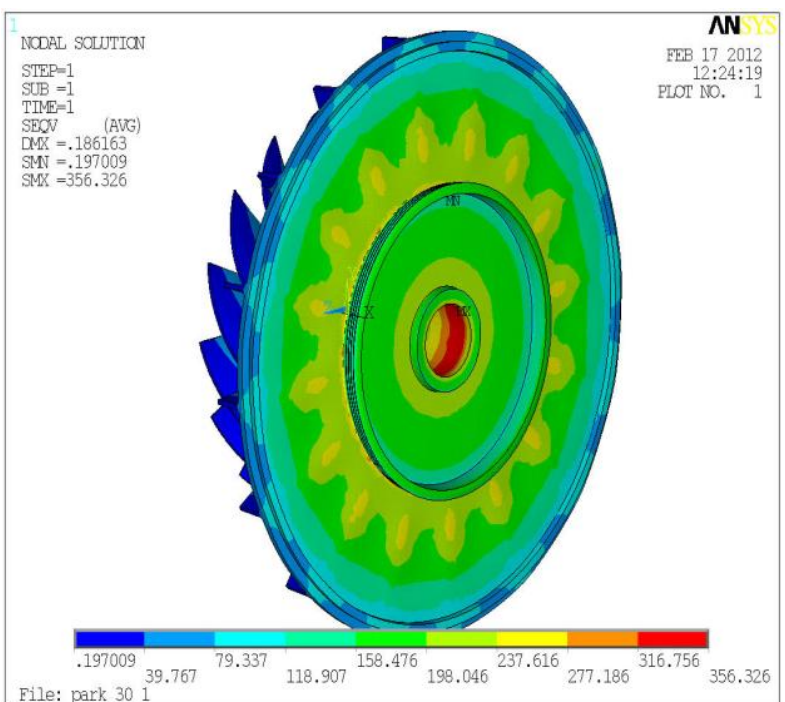

Fig.4 Von-Mises stress for Ti-6Al-4V. Max Von-Mises stress is occurs at hub i.e. $356.306 \mathrm{Mpa}$

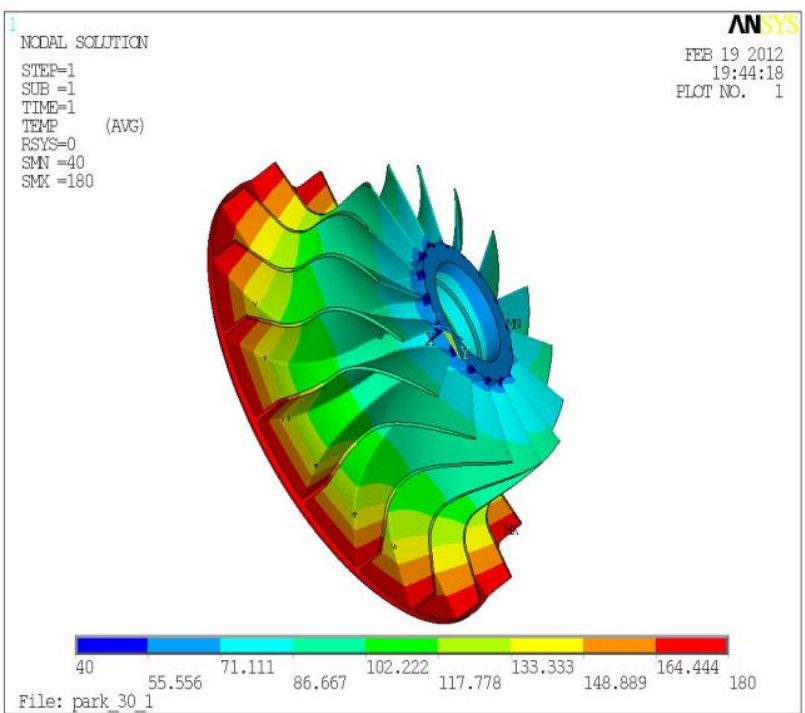

Fig.5 Temperature distribution for Au2gn. Max Temp is occurs at tip i.e. $180 \mathrm{C}$.

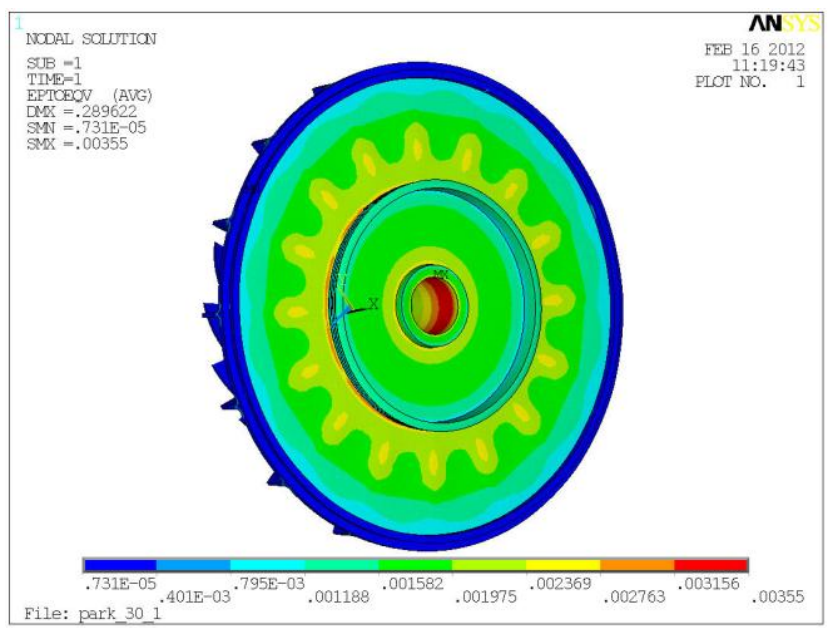

Fig.6 Total Mechanical Strain for Au2gn Max Strain is occurs at hub i.e.0.00355

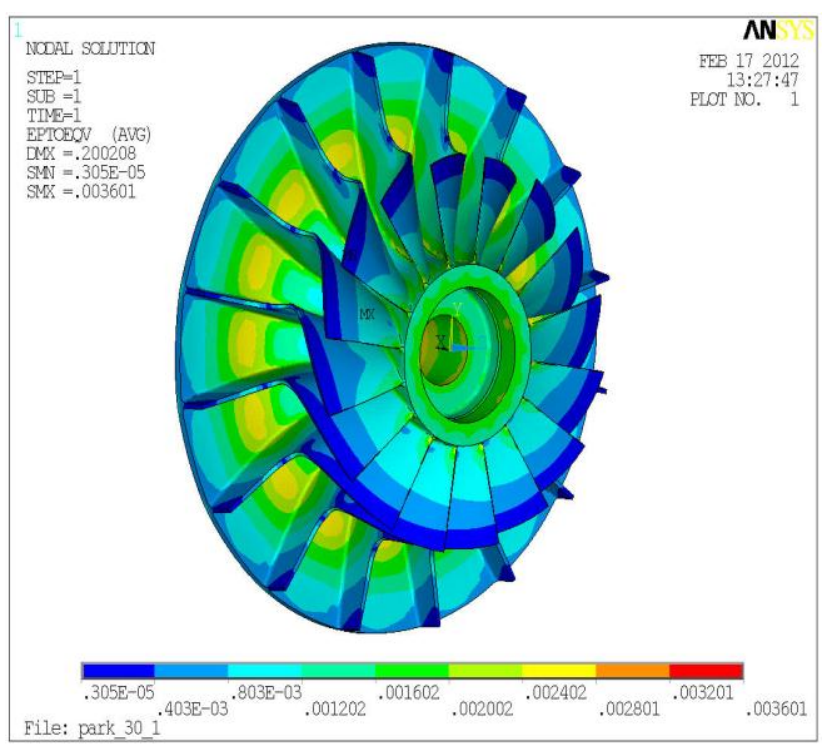

Fig.7 Total Mechanical strain for Ti-6Al-4V Max Strain is occurs at hub i.e. 0.003601 .

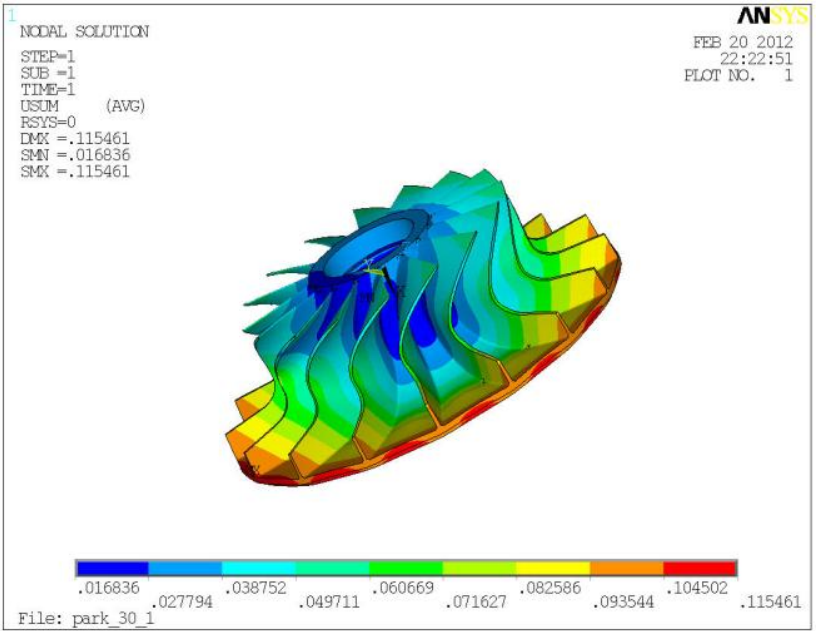

Fig.8 Displacement for Au2gn. Max displacement is occurs at tip i.e. $0.115461 \mathrm{~m}$.

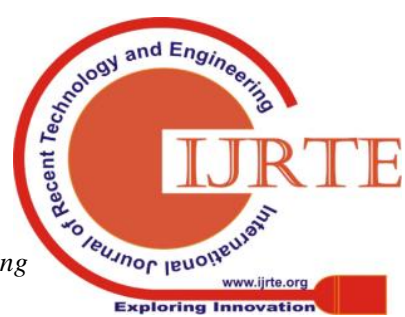


International Journal of Recent Technology and Engineering (IJRTE)

ISSN: 2277-3878, Volume-8, Issue-2S11, September 2019

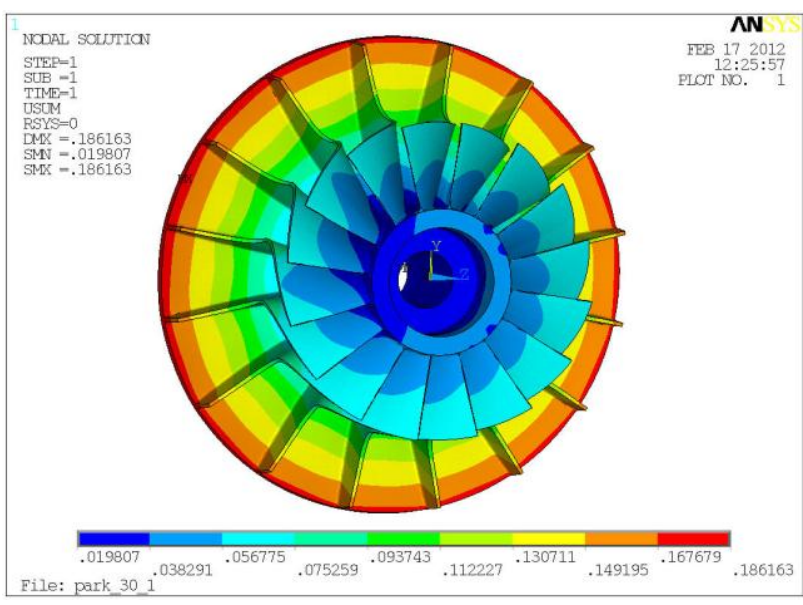

Fig.9 Displacement for Ti-6Al-4. Max displacement is occurs at tip i.e. $0.186163 \mathrm{~m}$.

\begin{tabular}{|c|c|c|}
\hline RESULT & Au2gn & Ti-6Al-4V \\
\hline Von-Mises stress in Mpa & 244.76 & 356.326 \\
\hline Total Mechanical Strain & 0.003505 & 0.003601 \\
\hline Displacement in m & 0.115 & 0.186 \\
\hline
\end{tabular}

\section{V.STRAIN BASED LIFE ESTIMATION}

In Material Science, Fatigue is the progressive and localized structural damage that occurs when material is subjected to cyclic loading. The impeller is subjected to low cycle fatigue (LCF).Cycles less than 1000 and typically stresses go beyond a material's yield strength into plasticity is known as LCF. In Strain-based life estimation, strain range is considered rather than Stress amplitude. Many methods are available for predicting the number of cycles to failure.

The relationship between the applied strain amplitude and fatigue life under uniaxial loading can be expressed by the following equation.

$\Delta \varepsilon=\left(3.5^{*}\left(\mathrm{UTS}-\sigma_{\text {mean }}\right) / \mathrm{E}\left(\mathrm{N}_{\mathrm{f}}\right)^{\mathrm{b}}+\varepsilon_{\mathrm{f}}^{0.6}\left(\mathrm{~N}_{\mathrm{f}}\right)^{\mathrm{c}}\right.$

where,

$\Delta \varepsilon \quad$-strain range in mm (from ANSYS)

UTS -Ultimate tensile strength in MPa

$\mathrm{Nf} \quad-$ No. of cycles to failure

ef -True fracture ductility

b -Fatigue strength exponent

c -Fatigue ductility exponent

\begin{tabular}{|c|c|c|}
\hline \multirow[t]{2}{*}{ Material } & $\begin{array}{c}\text { Number cycles to } \\
\text { failure }\end{array}$ & \\
\hline & Au2gn & $\mathrm{Ti}-6 \mathrm{Al}-4 \mathrm{~V}$ \\
\hline $\begin{array}{l}\text { Nf (Universal } \\
\text { slope method) }\end{array}$ & $2.13 * 10^{4}$ & $1.7 * 10^{5}$ \\
\hline $\begin{array}{l}\text { Nf (Four point } \\
\text { Correlation } \\
\text { Method) }\end{array}$ & $2.58 * 10^{5}$ & $1.33 * 10^{5}$ \\
\hline $\begin{array}{l}\text { Nf (Modified } \\
\text { Universal Me thod) }\end{array}$ & $1.17 * 10^{6}$ & $4.44 * 10^{7}$ \\
\hline $\begin{array}{l}\text { Nf (Uniform } \\
\text { Material Law) }\end{array}$ & $3.8 * 10^{5}$ & $1.4 * 10^{6}$ \\
\hline $\begin{array}{l}\text { Nf (Modified Four } \\
\text { point Correlation } \\
\text { Method) }\end{array}$ & $4.77 * 10^{6}$ & $4.76 * 10^{5}$ \\
\hline Nf (New Method) & $1.034 * 10^{5}$ & - \\
\hline
\end{tabular}

Table.1 Comparison of different strain-based life estimation methods

From the Values listed in the table, the Universal Slope Method gives good result.

\section{VI.MODAL ANALYSIS\& RESULTS}

Modal analysis is carried out to determine the natural frequencies and mode shapes of a structure. The natural frequencies and mode shapes are important parameters in the design of a structure for dynamic loading conditions. They are also required to do a spectrum analysis or a mode superposition harmonic or transient analysis.

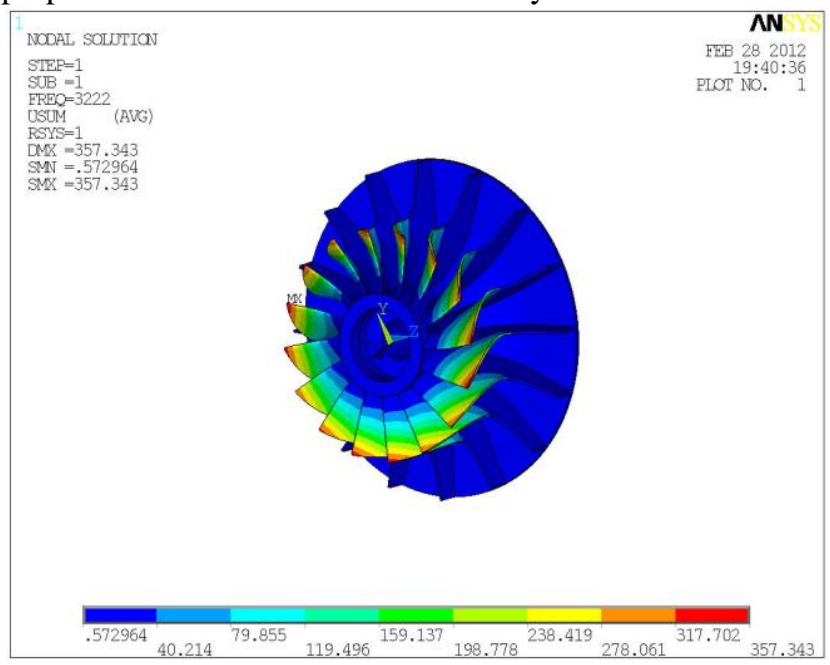

Fig.10 Mode Shape 1 


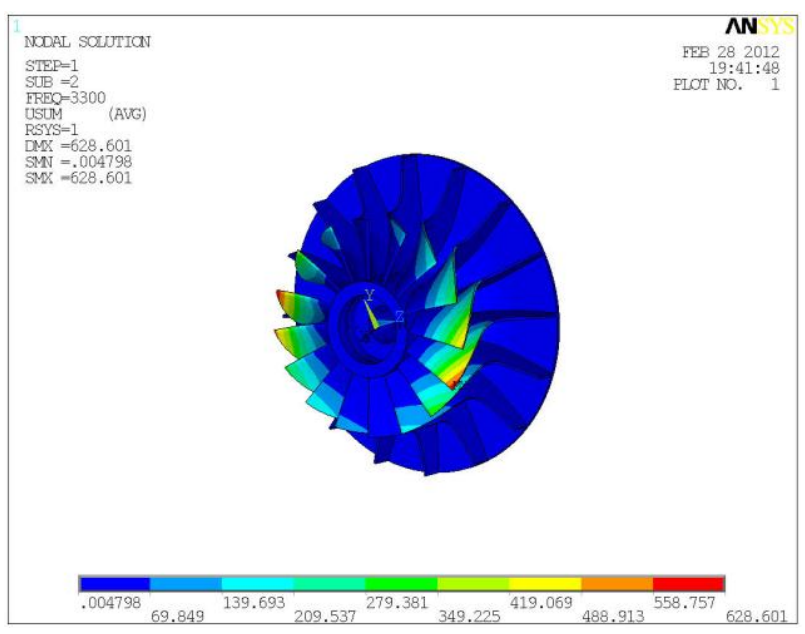

Fig.11 Mode Shape 2

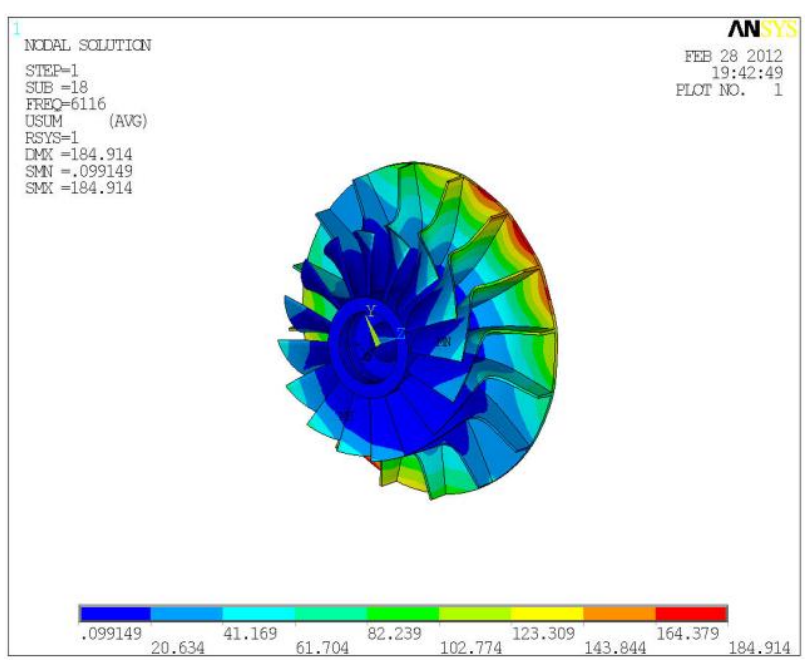

Fig.12 Mode Shape 3

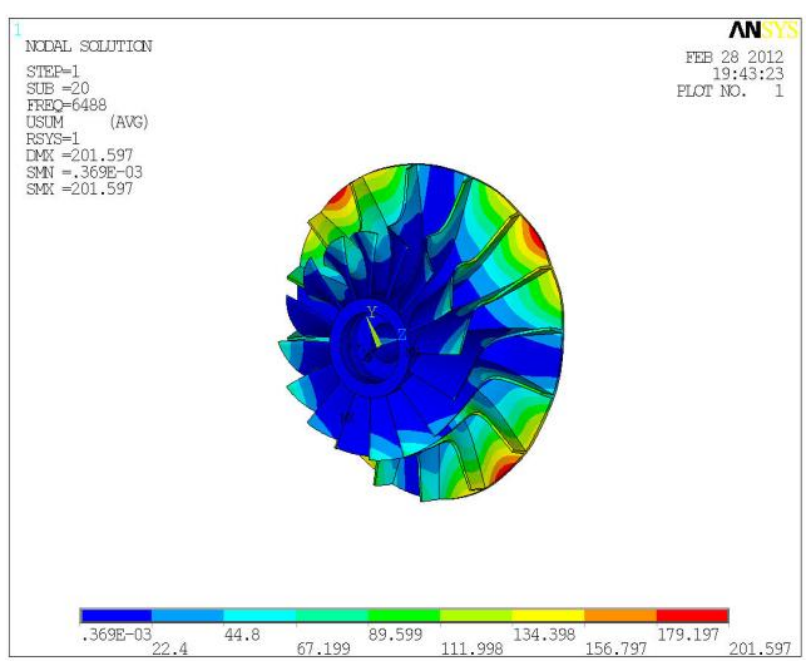

Fig.13 Mode Shape 4

\section{VII.TWO-DIMENSIONAL STRESS ANALYSIS}

Two dimensional impeller models are created in ANSYS 11 and impeller is to be assumed as axi-symmetric model. The impeller is discretized into four CST (Constant Strain Triangular Element) elements. Each element has three nodes and six degrees of freedom i.e. two degrees of freedom (Displacement and Rotation) for each node.

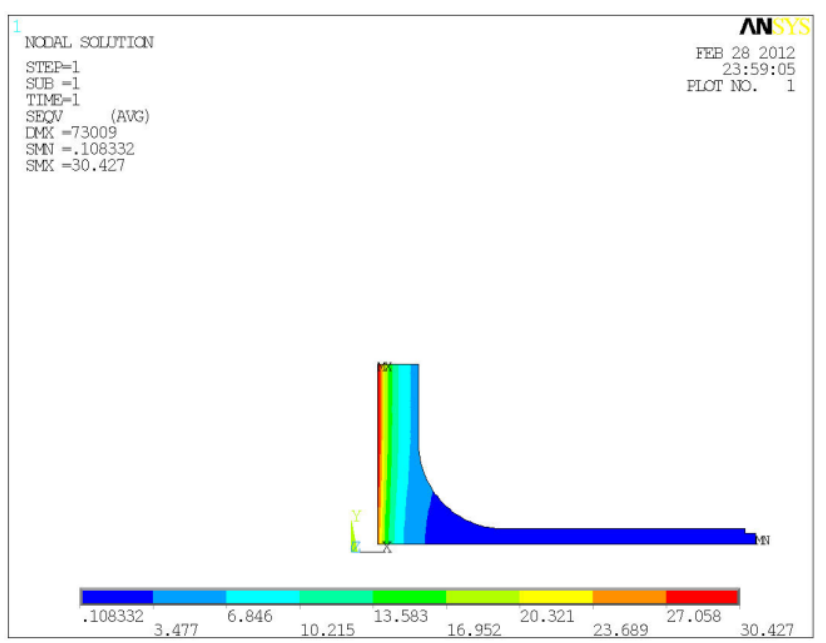

Fig.14 2-D Stress analysis. Max stress is found at hub i.e. 30.477Mpa.

The boundary conditions such as displacement and rotation about $\mathrm{Y}$-axis (rotation of nodes one, three and five are zero) are applied. The Current LS solver is used and the Von-Mises stress distribution is observed from Post-processor.

\section{VIII.CONCLUSION}

The stress analysis reveals that Ti6Al4V has good mechanical strength than Au2gn.The maximum stress occurs at the hub and gradually decreases from hub of the impeller to tip of the impeller. But it is seen that the maximum temperature is at tip of the blade. The results from strain-based life estimation were analyzed among which the universal slop method value is the best one that matches with exact value.

Modal analysis was carried out on the impeller and four mode shapes were identified during its progress. When Starter comes into operation during the starting cycles, its operation is restricted to 60 seconds (start - stop cycle). Based on the analysis, it can have 100000 starts. Mode shapes and corresponding frequencies were studied.

Natural frequency $(\omega n)=3222 \mathrm{~Hz}$.

Third Model seems to be critical based on its frequency and relative displacement.

\begin{tabular}{|c|c|c|}
\hline Material & Au2gn & Ti6Al4V \\
\hline Stress Range $(\Delta \sigma) \mathrm{MPa}$ & 244.286 & 356.129 \\
\hline $\begin{array}{l}\text { Stress Amplitude(бa) } \\
\text { MPa }\end{array}$ & 122.143 & 178.065 \\
\hline Mean stress(om) $\mathrm{MPa}$ & 122.617 & 178.261 \\
\hline Load ratio(R) & 0.001936 & 0.0005529 \\
\hline
\end{tabular}

Hence, Ti6Al4V has good mechanical strength than Au2gn.

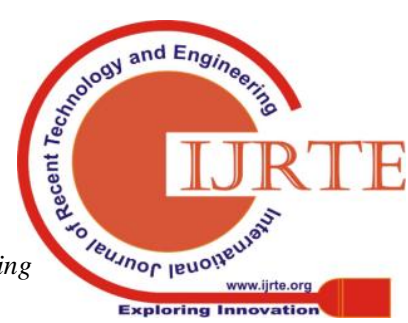




\section{REFERENCES}

1. Ganesan. V, Gas Turbines, Second Edition, Tata McGraw Hill Education Private Limited, New Delhi, 2009

2. H. Cohen, G.F.C. Rogers and H.I.H. Saravanmuttoo, Gas Turbine Theory, Fifth Edition, Pearson Education Ltd, 2009

3. Philip P. Walsh and Paul Fletcher, Gas Turbine Performance, Blackwell Publishing Company, 2004

4. Jack .D Mattingly, Elements of Gas Turbine Propulsion, Tata McGraw Hill Publishing Co. 2005

5. E. Irwin Treager, Aircraft Gas Turbine Engine Technology, 3rd Edition 1995 'ISBN- 00201828

6. KlauseHunecke, Jet Engines Fundamentals of Theory, Design and Operation, Motors book international publishers \& Wholesalers, 6th edition, 1997.

7. Bannantine, J.A., Comer, J.J. and Handrock, J.L. 1990, Fundamentals of Metal Fatigue Analysis, Prentice Hall.

8. MehaSetiya , Dr. Beena D. Baloni, Dr. Salim A. Channiwala. 2015. "Structural analysis of load compressor blade of aircraft auxiliary power unit".International Journal of Scientific \& Engineering Research, Volume 6, Issue 2, February-2015 .

9. V.R.S.M. Kishore Ajjarapu, K. V.P.P.Chandu, D.M.MohanthyBabu .2012. "Design and Analysis of the Impeller of a Turbocharger for a Diesel" , International Journal of Advanced Engineering Research and Studies, Volume 2, Issue 1, Oct.-Dec.,2012.

10. A Syam Prasad, BVVV LakshmipathiRao, ABabji, Dr P Kumar Babu. 2013. "Static and Dynamic Analysis of a Centrifugal Pump Impeller", International Journal of Scientific \& Engineering Research, Volume 4, Issue 10, October-2013. 